\title{
An ANP Based Evaluation Model for Invoicing Solutions
}

\author{
Hongyang $\mathrm{Chu}^{1, *}$, Yueting $\mathrm{Chai}^{1}$, Yi Liu ${ }^{1}$ and Hongbo Sun ${ }^{1,2}$ \\ ${ }^{1}$ National Engineering Laboratory for E-Commerce Technologies \\ Tsinghua University, Beijing 100084, China \\ ${ }^{2}$ DNSLAB, China Internet Network Information Center, Beijing 100190, China \\ *chuhy30804@aliyun.com
}

\begin{abstract}
In recent years, electronic invoicing has come into sight and plays a vital role in a lot of businesses. Under this circumstance, enterprises need to select from either electronic invoicing solutions or paper-based ones. The electronic invoicing solution can be a selfbuilt or a commercial one. In this paper, an ANP-based evaluation model is proposed aiming at addressing this selection problem. Cost and Effectiveness are the two basic determinants in this model to prioritize invoicing solutions. Cost is categorized by three dimensions: one-off cost, monthly cost and unit cost. Effectiveness is classified into four dimensions: customer experience, supplier performance, enterprise business and invoicing performance. Each dimension has a subset of several elements that give a more specific description of the invoicing process. And the relative importance of these elements and dimensions are calculated by numerical pairwise comparisons which especially pay attention to the interdependencies of dimensions. The overall evaluation of alternative invoicing solutions can be achieved by this model so as to assist enterprise managers to conduct decision-makings. In the end a pilot case about a Chinese $e$ commerce enterprise demonstrates the feasibility of the proposed approach.
\end{abstract}

Keywords: invoicing solution; evaluation model; ANP-Analytic Network Process

\section{Introduction}

E-commerce, known as "commercial activities conducted through an exchange of information generated, stored, or communicated by electronic, optical, or analogous means" [1], has experienced a rapid development in our daily lives. For example, in 2011 the transaction amount in Chinese e-commerce market reached 6 trillion Yuan, with a growth of $33 \%$ over 2010, while the B2B e-commerce market transaction amount reached 4.9 trillion Yuan, with a growth of 29\% [2]. It owns obvious advantages over other businesses, for it can reduce the duration of the business process, enable broader access to products and services, and speed up the exchange of business documents and information, and so, in the long run, cut costs and increase profits [3].

As the most important document exchanged between trading partners [4], invoices also play an important role in e-commerce. However, in some aspects paper-based invoices cannot satisfy the requirements of e-commerce. For example, most e-commerce processes need to be done within a short period of time, but paper-based invoicing solutions cannot react rapidly due to involved distributed transactions. Therefore, the paper-based invoicing processes do harm the efficiency of online transactions. What is more, paper-based invoicing related cost is also an annoying problem. The usage, delivery and storage of paper documents are quite expensive, especially for those enterprises who own a large number of trading volume. 
Under this circumstance, electronic invoicing, defined as the sending or making available of an invoice and its subsequent processing and storage, wholly by electronic means [5], has come into practice among e-commerce participators. At present, electronic invoicing is applying and spreading in EU, South America and some other nations [6]. In China, electronic invoicing has just started, and only few large enterprises have used electronic invoice in the experimental stage [7].

Electronic invoicing brings benefits to enterprises, including a rapid and accurate invoicing process and a reduction of cost, and enterprises may enjoy further opportunities for improving the efficiency of e-commerce processes and converting old paper-based documents to electronic form [8]. At the same time, electronic invoicing also has special requirements, for example, related equipment investment, IT infrastructure and information processing capacity [9]. Thus, enterprise manager has to make a decision whether to adopt electronic invoicing or not through a comprehensive consideration, instead of an analysis from a single aspect.

If enterprises decide to use electronic invoicing, they can take the options of establishing an self-built electronic invoicing, relying on application service providers (ASP) or outsourcing the whole electronic invoicing process [10]. For the latter two, keeping in view of the growing trend of electronic invoicing, a wide variety of services is provided by different vendors. Till 2011, about 530 service providers and another 200 software companies are offering their electronic invoicing solutions in Europe [6]. Enterprise needs to select a suitable solution from these alternatives, according to its demands.

Enterprise managers must consider all the influence factors and analyze the tradeoff among the several criteria [11], when they are deciding to adopt electronic invoicing or not, or when they are choosing an appropriate electronic invoicing solution. The evaluation of invoicing solutions is a multi-criteria problem, in which the priority of criteria depends on the current situation of the given enterprise [12]. The problem has some special characteristics due to the specificity of invoicing process: First, the criteria that used to evaluate an invoicing solution vary according to the region and business scope of enterprise, and even time. Second, the criteria are not independent, and they have influence on each other.

Considering these features, most decision-making models are not suitable for the evaluation of invoicing solutions. Artificial intelligence and probabilistic approaches require sufficient data to achieve a result, but it is hard to have enough reference data due to the various demands of enterprises. Mathematical programming cannot handle with the constant changing criteria and their interdependencies. Hence, in this paper, a special linear weighting model, known as analytic network process (ANP), is introduced to solve the multi-criteria problem in evaluating invoicing solutions.

ANP is the generalization to dependence and feedback of analytic hierarchy process (AHP) [13]. Considering the interaction of various criteria in the selection of invoicing solutions, this paper prefers ANP, which is fundamentally a process of laying out a structure of all the essential criteria that influence the decision. Then, numerical pairwise comparison judgments are used to express people understanding of the importance or likely influence of these elements on the final outcome. The syntheses of different sets of pairwise comparisons are used to obtain the priorities of alternatives [14].

The remainder of this paper is organized as follows. Section II analyses the stateof-art of ANP method with some typical models and practical applications. Section III proposes the criteria on the evaluation of invoicing solutions. In Section IV, the ANP-based evaluation model is constructed and a case study of a Chinese ecommerce enterprise is given. In Section V the features of this model are concluded. 


\section{Literature Review}

The original ANP was proposed by Saaty in 1996 [15], as the extension of AHP [16]. Based on AHP, Berutti proposed a provider selection model of electronic invoicing in 2012, focusing on the analysis of service outsourcing [17]. It was structured with indexes including costs, solutions, capabilities and business. Cost was independently evaluated, and the rest was evaluated by AHP. The model worked well, but it required objective evaluations of the decision criteria, and interdependencies of the criteria were not considered.

In order to solve the decision making problem in outsourcing a firm's application, Saaty presented an specific ANP model with four concerns: benefits $(B)$, opportunities $(O)$, costs $(C)$ and risks $(R)$ in 2004 [18], and provided an outsourcing case study in 2006 [19]. In this model, the rating of each concern was derived through pairwise comparisons, and the priorities of the alternatives were synthesized by using a ratio formula $B O / C R$ or a total formula $b B+o O+c C+r R$.

This BOCR model has been adopted in various fields. In terms of invoicing solution evaluation, Kinijarvi adopted the ANP model to aid a buyer company in prioritizing suppliers for adopting electronic invoicing in 2011 [20]. The case study was a textile company in Finland, and the business was valued in BOCR. In other aspects, Erdoğmuş used the model in 2005 to study the renewal of a transaction processing system for enhanced efficiency and operation quality in a university cooperative [21]. Dikmen focused on project appraisal and selection in 2007, to solve a real highway projects that were in the investment agenda of Turkish government [22]. Liang proposed a project selection model of an enterprise information system with regard to BOCR in 2008 [23], with a case study of manufacturing executive system project selection in a Chinese undershirt manufacturer. Sun presented a selection evaluation indices system of thirdparty logistics service provider in 2010 [24]. Ustun proposed a multi-period inventory lotsizing scenario supplier selection solution in 2012 [25], using an integration of ANP and achievement scalarizing functions.

Instead of the BOCR model, there are many other approaches to deal with service evaluations. In 1999, Meade proposed a four layer ANP model, including determinants, dimensions, enablers and alternatives, to analyze project alternatives for agile manufacturing process [26]. The interdependencies of enablers were considered and a supermatrix was formed according to this relationship. Using a similar process, Meade presented a method for $R \& D$ project evaluation that allowed for the consideration of important interactions among decision levels and criteria in 2002 [27]. On the basis of this, Jharkharia proposed an ANP approach for selecting logistic service providers in 2007 [28], and Chen applied it in a case study of the industry investing in southeast Asia in 2011 [29].

The BOCR model helps to solve many problems, but it is not suitable for the evaluation of invoicing solutions. First, benefits in the BOCR model are referred to tangible and positive factors, and costs are referred to tangible and negative ones [30]. But in invoicing process, there are few benefits that can be easily expressed in monetary terms. Second, opportunities and risks are used to deal with intangible factors, but it is quite difficult to determine a factor to be a risk or an opportunity in invoicing process. It can be seen in the model of Kivijarvi [20] that, in order to structure the BOCR model, many detailed factors were vaguely defined, such as company image, resulting in that the model could not give accurate description of invoicing process. Hence, the BOCR model is not used for invoicing solution selection in this paper.

Unlike BOCR, the method proposed by Meade is free to choose determinants that the evaluation concerns. In this way, the evaluation of invoicing solutions could be expressed through Cost and Effectiveness. However, Meade considered the interdependencies of basic elements, since the elements had relations with each other. As a result, a pairwise 
comparison matrix must be structured for every element, so the model required a lot of computational work. In the evaluation of invoicing solutions, the elements are not closely related, so this paper considers the interdependencies of dimensions, which are at a higher layer than elements.

Based on the work mentioned above, this paper proposes an ANP-based model for the evaluation of invoicing solutions. This model lays out a structure of seven dimensions and all the essential criteria are used to describe the dimensions as elements. The interdependencies of dimensions are considered, instead of those of elements. Then, through pairwise comparisons, the priorities of different solutions are calculated.

\section{Criteria for the Evaluation of Invoicing Solutions}

In the ANP model, enterprise needs a comprehensive consideration about the influences of various criteria while prioritizing invoicing solutions. A solution is evaluated through the combination of all related criteria, to sum up the overall value which the enterprise could acquire. Then, the alternatives are compared and sorted. Therefore, enterprise could obtain the optimal. In the first step, the criteria for the evaluation of invoicing solutions have to be selected.

In this paper, Cost and Effectiveness are introduced to be the two determinants of the evaluation model. Since enterprise prefers lower cost and better effectiveness, the overall will be calculated in a total formula: $e E d C$, as $E$ and $C$ stand for Effectiveness and Cost, and $e$ and $c$ are the relative weights.

\subsection{Cost}

In this determinant, all types of cost that are involved in supporting the invoicing solution are considered, whereas twelve of them are selected to describe the enterprise expenditures. Some other costs are ignored because they have no effect or minimal effect on enterprise.

Cost is divided into three dimensions: One-off cost, monthly cost and unit cost. Oneoff cost is paid only once, monthly cost is paid periodically, and unit cost is related to every single invoice. This classification has the advantage to distinguish the different requirements among enterprises.

3.1.1. One-Off Cost: Enterprise has to accomplish installation and other preparatory work before or shortly after the invoicing solution comes into practice. One-off cost includes four elements: relationship building cost, installation cost, employee training cost and advertising cost.

Relationship building cost: Cost to form a satisfactory relationship with the solution supplier, including financial costs, human resources, and coordinating costs [31].

Employee training cost: The practical operation of invoicing process often requires a further training for employees to utilize the solution. The training is about the usage and maintenance of equipments, invoicing process, fault solutions and so on.

Advertising cost: In some special cases, enterprise will publicize the invoicing solution by advertisement on social media. Feasible advertising cost helps enterprise to attract more customers and partners. 


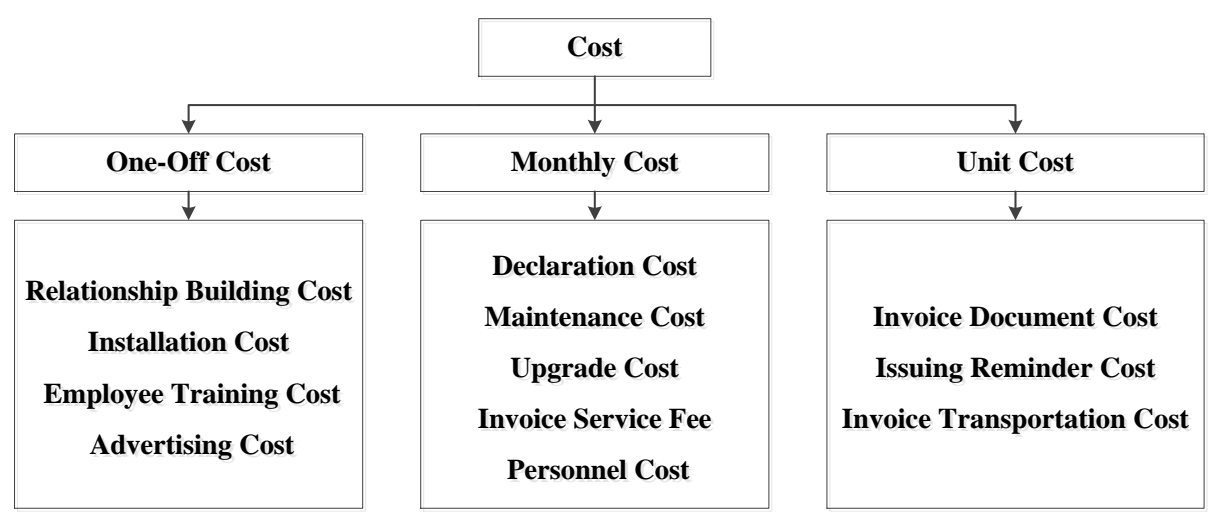

Figure 1. The Structure of the Criteria of Cost

3.1.2. Monthly Cost: Enterprise should pay for involved monthly costs at intervals, in order to sustainably utilize an invoicing solution. Monthly cost includes five elements: declaration cost, maintenance cost, upgrade cost, invoice service fee and personnel cost.

Declaration cost: Cost generated while enterprise pays taxes in legal way, which is also known as compliance cost [33]. Declaration cost includes paper cost of tax declaration forms, copy of account books and related invoices, and labor cost on submitting these documents.

Maintenance cost: In order to ensure the invoicing solution works well, enterprise is responsible for regular maintenance of related equipment and providing consumables.

Upgrade cost: Cost of upgrading to the new versions of the solution, usually includes the update of hardware, software and network.

Invoice service fee: Monthly, seasonally or yearly fee that enterprise pays to invoicing solution suppliers, so as to obtain the usage of invoice service. Invoice service fee take account of invoice quantities, service qualities, local condition, etc.

Personnel cost: Cost linked to personnel management, including salaries, health insurances and pension benefits of employee [30].Enterprise pays personnel cost to get the labor for the utilization of the invoicing solution.

3.1.3. Unit Cost: The reduction in unit cost would bring telling effects, as Europe has enjoyed the benefits of electronic invoicing in cutting down the cost of every invoice from 30-50 Euros to 1 Euro [6]. Unit cost includes three elements: invoice document cost, issuing reminder cost and invoice transportation cost.

Invoice document cost: Cost related to documents that record the invoice information. Invoice document is a piece of paper, or electronic data.

Issuing reminder cost: In large enterprises that all sessions of the whole trading process are separately managed by different departments, employees that are responsible for handling transactions should take measures to remind those responsible for issuing invoices. Issuing reminder cost is the consequent document cost and labor cost.

Invoice transportation cost: On delivery, by mail and personnel are three main distributions of physical invoices. And emails, electronic presentment, or messaging protocols are for electronic invoices [34].

\subsection{Effectiveness}

In this determinant, effectiveness from all aspects is considered, whereas fifteen of them are selected for the evaluation of invoicing solutions. All of them are generic elements that describe the characteristics of an invoicing process.

Effectiveness is divided into four dimensions: Customer experience, supplier performance, enterprise business and invoicing performance. In invoicing process, 
customer, supplier and enterprise are the three participators, so customer experience, supplier performance and enterprise business are used to describe Effectiveness.

3.2.1. Customer Experience: As payers in transactions, today's customers demand cheaper, high quality products, on-time delivery and excellent after-sale services [35]. Customer experience is the totality of the experience of a payer when receiving and using invoices. It includes three elements: invoice transportation time, after-sale service quality and reimbursement service quality.

Invoice transportation time: The average duration to transport invoice from enterprise to customers. By improving paper-based invoicing to electronic invoicing, delivery time changes from several days to a few seconds.

After-sale service quality: Another feature of invoicing is that customer could ask for after-sale service, such as installation, maintenance, return and exchange of products. Customer is interested in the quality of after-sale service that based on the use of invoice.

Reimbursement service quality: The convenience degree of handling reimbursement by submitting invoice to related auditors.

3.2.2. Supplier Performance: Supplier performance is the general information of invoicing solution supplier, and it forms a basic evaluation of the supplier. Supplier performance includes four elements: previous experience, supplier reputation, solution compatibility and environmental performance.

Previous experience: Prior experience that related to provide invoicing solutions is an added advantage to the supplier. The history of handling taxation affairs and other IT services is also considered.

Supplier reputation: Reputation of the supplier includes references from previous clients, peer review and related quality certificates. Further, financial status and volume of business are also evaluated to demonstrate a more specific image of given supplier.

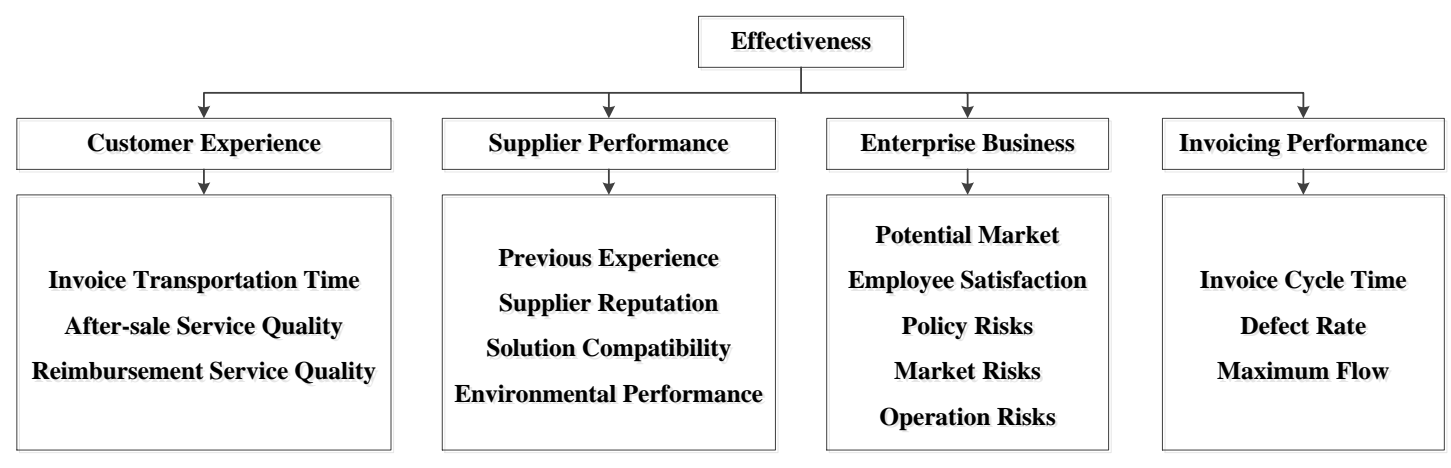

Figure 2. The Structure of the Criteria of Effectiveness

Solution compatibility: Compatibility between enterprise and solution supplier. The main considerations are the difficulties of integrating given invoicing solution into current business process and the distinction in technology, strategic and even geographic location.

Environmental performance: Environmental pressure is increasing, resulting in many enterprises (mainly large enterprises) beginning to consider environmental issues and the measurement of their suppliers' environmental performance [36].

3.2.3. Enterprise Business: New invoicing solutions bring changes to enterprises. These opportunities and risks will have influences on the future development. Enterprise business includes five elements: potential market, employee satisfaction, policy risks, market risks and operation risks. 
Potential market: A satisfying solution provides a better user experience, which facilitates to attract more customers. Further, it may enlarge the market, by establishing cooperative relationship with potential partners that shares a similar strategic.

Employee satisfaction: The presence of dissatisfied employees at the enterprise may lead to strike, lockouts, sabotage, and other such unwanted activities [28]. Thus, the new invoicing solution should pay attention on employee morale and keep invoicing process in order.

Policy risks: In many regions, electronic invoice is not clearly recognized in law. Therefore enterprises should consider the possibility that electronic invoicing might be forbidden someday.

Market risks: New invoicing solutions may not be accepted by the market. Under this situation, enterprises will suffer a reduction of customers and partners.

Operation Risks: In daily operation of invoicing solutions, enterprise has to deal with unexpected incidents. For example, the stored invoices may be struck by natural disaster or intentional attack, resulting in a data missing, which will bring a lot of loss.

3.2.4. Invoicing Performance: Several performance parameters are given to evaluate the invoicing process provided by given solution. Invoicing performance includes three elements: invoice cycle time, defect rate and maximum flow.

Invoice cycle time: The average duration of issuing an invoice. It starts from the end of the transaction, and ends at the instant when the invoice is transported to customers.

Defect rate: With good staff and strict operation, errors on invoice could be reduced. However, in different invoicing solutions, especially changing from labor invoice to electronic invoice, a noticeable change will take place.

Maximum flow: The ability to handle invoicing process in parallel is required in large enterprises. Maximum flow is a significant parameter that is always considered with invoice cycle time. The multiply result is the maximum throughput of given invoicing solution.

\section{The Evaluation Model}

In the previous section, the criteria for the selection of invoicing solutions are listed, and altogether there are twenty seven factors used to describe an invoicing solution. Enterprises should comprehensively consider the influences of these various factors while prioritizing solutions, from the aspects of Cost and Effectiveness.

ANP is introduced to fulfill the multi-criteria decision making model. First of all, the criteria are structured to develop a model, where the connection reflects the relationship between different layers. Then pairwise comparison is used to figure out the weight of each criterion, and the character of each solution. Finally, the overall of every invoicing solution is calculated by Effectiveness minus Cost, which provides the evaluation of given solution. In this section, the detailed steps are given with a case study in China.

In China, the beginning of electronic invoicing and the emergence of Golden Tax Project give enterprise more options. Manually issuing invoice is the most traditional way, but there are still small enterprises benefiting from its low demand and low costs. Golden Tax Project provides a tax control machine to enterprise, through which financial personnel could submit transaction information into a computer [37, 38], but invoices are still printed on paper. On electronic invoicing aspects, some industry-leading B2C enterprises have established their own electronic invoicing systems, or adopted electronic invoicing from service providers.

The case study of the decision-making model has been demonstrated for a large-scale B2C enterprise in China, as the number of invoices issued every day has ranged over 10000. The enterprise holds advanced IT capabilities and infrastructures for online trading, including ERP system, in-house logistics, etc. And the enterprise has a strong 
desire to take measures to attract customers and partners, regardless of the related cost. Currently, the enterprise is adopting Golden Tax Project, which uses tax control machine to issue paper-based invoices. The problems laying ahead for given enterprise is to evaluate different invoicing solutions and decide to adopt electronic invoicing or not.

\subsection{ANP Structure}

A structure composed of decision goal, criteria and alternatives is the precondition of the application of ANP. Figure 3 illustrates this ANP hierarchy structure on the basis of the twenty seven criteria. The goal of this model is to give evaluations toward different invoicing solutions. Two determinants are considered, including Cost and Effectiveness. One-off cost, monthly cost and unit cost, and customer experience, supplier performance, enterprise business and invoicing performance are dimensions that are considered as components of Cost and Effectiveness. Then twenty seven elements are considered as the elements of dimensions, which are also the criteria for the evaluation.

A decision problem involving feedback arises often in practice [30]. Despite the structure is hierarchical, there always have interdependencies of criteria, which means that elements in different dimensions may have influence on each other. However, the looser network structure of ANP makes it possible to model various selection criteria without a concern for the interdependency [39].

After the criteria have been organized, three invoicing solutions are compared as alternatives, namely A, B, and C. Invoicing solution A is to continue using paper-based invoice, which is issued by tax control machine of the Golden Tax Project. Invoicing solution $\mathrm{B}$ is to establish self-built electronic invoicing, which requires a large amount of money and manpower. Invoicing solution $\mathrm{C}$ is to adopt an electronic invoicing solution provided by a third party provider. The provider has a ten year experience in invoicing affairs and their business includes notes management, data processing and security printing.

\subsection{Pairwise Comparison of Dimensions}

After building the ANP structure, this model continues to obtain the important or likely influence of the dimensions, elements and alternatives. In order to computer the weights for different criteria, a pairwise comparison matrix is created. The matrix is an $\mathrm{m} \times \mathrm{m}$ real matrix, where $\mathrm{m}$ is the number of criteria. The matrix entry $a_{i, j}$ is the relative importance of the $i$ th criterion with respect to the $j$ th criterion. A numerical scale from 1 to 9 is used for $a_{i, j}$ when the $i$ th criterion is more important than the $j$ th criterion, and a numerical scale from 1 to $1 / 9$ is used for $a_{i, j}$ when the $j$ th criterion is more important than the $i$ th criterion.

This pairwise comparison method is proposed by Saaty [16]. To accomplish the method, judgments from a group of experts are integrated to avoid the biased attitude in some comparisons. There are several ways for including the views and judgments of group members in the pairwise comparison, including consensus, vote or compromise, geometric mean of judgments and a separate mode 1 [40].

The pairwise comparison must go through a consistency test. After that, the local priority vectors, known as e-vectors, are derived as the eigenvector related to the maximum eigenvalue of the matrix. Another method is to raise the pairwise comparison matrix to powers after normalizing the rows. 


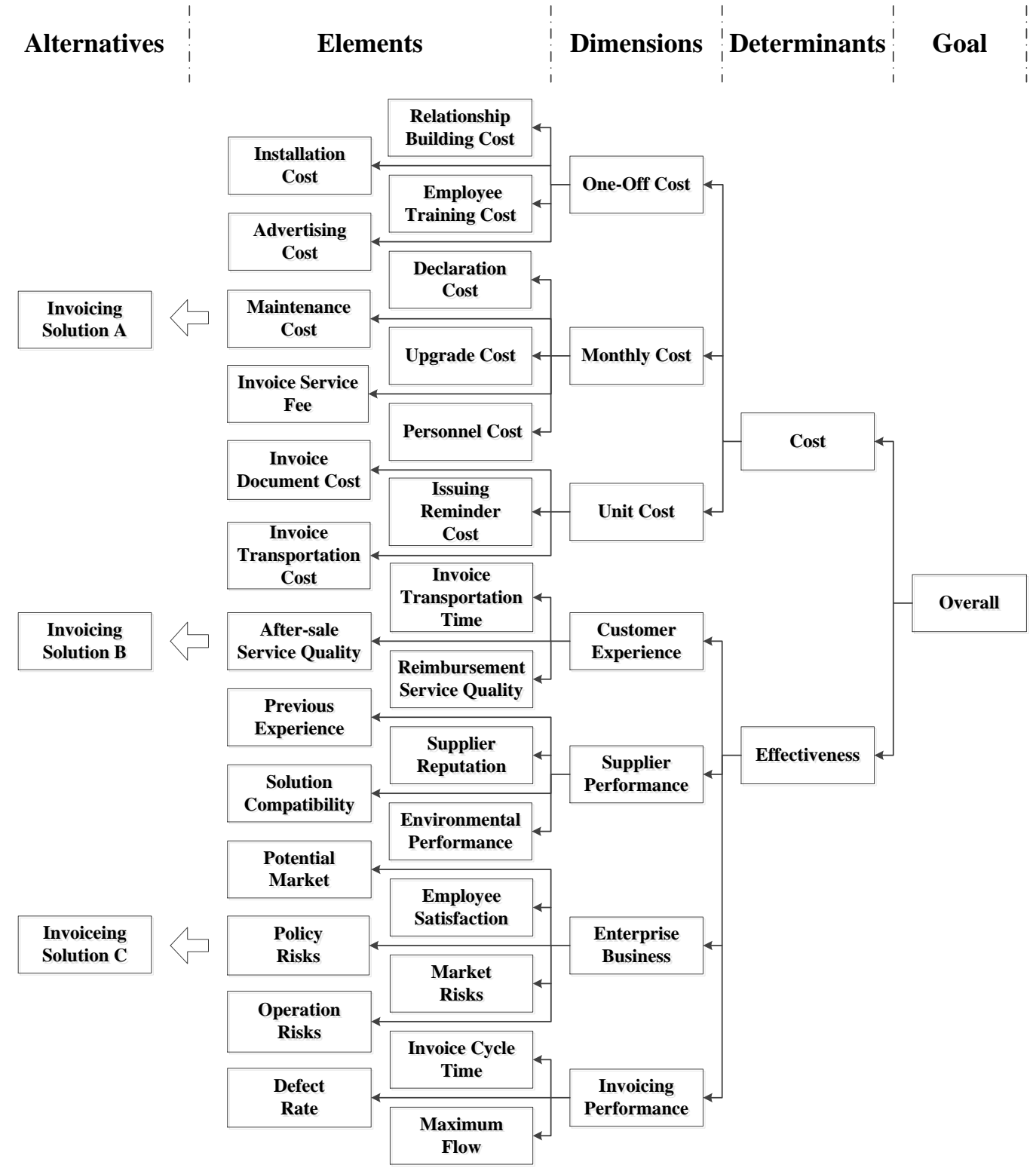

Figure 3. The Structure of ANP Based Model

In this step, a series of pairwise comparisons are proposed to establish the relative importance of dimensions with respect to the overall evaluation. Table 1 illustrates the pairwise comparison matrix for the present enterprise. For the matrix entry $a_{i, j}$, the question asked to the experts is "considering the influence on the overall, what is the relative importance of dimension $i$ when compared to dimension $j . "$

From Table 1, it is observed that the relative importance of unit cost when compared to invoicing performance with respect to the overall is three. From the derived e-vectors, it is observed that unit cost has the maximum influence (0.24870) and one-off cost has the minimum influence (0.03037). For clarity, the relative importance of dimensions $i$ in influencing the overall is defined as $D_{i}$.

Table 1. Pairwise Comparisons of Dimensions

\begin{tabular}{lllllllll}
\hline & OOC & MC & UC & CE & SP & EB & IP & e-vectors \\
\hline One-off cost (OOC) & 1 & $1 / 5$ & $1 / 7$ & $1 / 7$ & $1 / 5$ & $1 / 4$ & $1 / 3$ & $\mathbf{0 . 0 3 0 3 7}$ \\
Monthly cost (MC) & 5 & 1 & $1 / 2$ & $1 / 2$ & 1 & 1 & 2 & $\mathbf{0 . 1 3 7 2 0}$ \\
Unit cost (UC) & 7 & 2 & 1 & 1 & 2 & 2 & 3 & $\mathbf{0 . 2 4 8 7 0}$
\end{tabular}




\begin{tabular}{lllllllll} 
Customer experience (CE) & 7 & 2 & 1 & 1 & 2 & 2 & 2 & $\mathbf{0 . 2 3 5 9 0}$ \\
Supplier performance (SP) & 5 & 1 & $1 / 2$ & $1 / 2$ & 1 & 1 & 2 & $\mathbf{0 . 1 3 7 2 0}$ \\
Enterprise business (EB) & 4 & 1 & $1 / 2$ & $1 / 2$ & 1 & 1 & 1 & $\mathbf{0 . 1 2 0 1 0}$ \\
Invoicing performance (IP) & 3 & $1 / 2$ & $1 / 3$ & $1 / 2$ & $1 / 2$ & 1 & 1 & $\mathbf{0 . 0 9 0 5 2}$ \\
\hline
\end{tabular}

Inconsistency 0.00856

\subsection{Pairwise Comparison for Interdependencies}

In order to deal with the interdependencies of dimensions, pairwise comparisons under every pair of dimensions have to be calculated.

In this step, a series of pairwise comparisons are proposed to establish the relative importance of dimensions with respect to a selected dimension. Table 2 illustrates the pairwise comparison matrix that the selected dimension is one-off cost. When the selected dimension is $\mathrm{k}$, for the matrix entry $a_{i, j}$ in the matrix, the question asked to the experts is "considering the influence on dimension $k$, what is the relative importance of dimension $i$ when compared to dimension $j$." Altogether there are seven such pairwise comparison matrixes, one for each of the seven dimensions.

From Table 2, it is observed that the relative importance of supplier performance when compared to customer experience with respect to one-off cost is two. From the derived e-vectors, it is observed that one-off cost has the maximum influence (0.39989) and both monthly cost and unit cost have the minimum influence $(0.04535)$.

Table 2. Pairwise Comparisons of Dimensions under One-Off Cost

\begin{tabular}{lllllllll}
\hline & OOC & MC & UC & CE & SP & EB & IP & e-vectors \\
\hline One-off cost (OOC) & 1 & 9 & 9 & 3 & 2 & 6 & 3 & $\mathbf{0 . 3 9 9 8 9}$ \\
Monthly cost (MC) & $1 / 9$ & 1 & 1 & $1 / 2$ & $1 / 4$ & $1 / 2$ & $1 / 3$ & $\mathbf{0 . 0 4 5 3 5}$ \\
Unit cost (UC) & $1 / 9$ & 1 & 1 & $1 / 2$ & $1 / 4$ & $1 / 2$ & $1 / 3$ & $\mathbf{0 . 0 4 5 3 5}$ \\
Customer experience (CE) & $1 / 3$ & 2 & 2 & 1 & $1 / 2$ & 1 & $1 / 2$ & $\mathbf{0 . 0 9 3 3 5}$ \\
Supplier performance (SP) & $1 / 2$ & 4 & 4 & 2 & 1 & 2 & 1 & $\mathbf{0 . 1 7 7 2 4}$ \\
Enterprise business (EB) & $1 / 6$ & 2 & 2 & 1 & $1 / 2$ & 1 & $1 / 2$ & $\mathbf{0 . 0 8 3 8 9}$ \\
Invoicing performance (IP) & $1 / 3$ & 3 & 3 & 2 & 1 & 2 & 1 & $\mathbf{0 . 1 5 4 9 2}$ \\
\hline
\end{tabular}

Inconsistency 0.00622

\subsection{Super-Matrix of Dimensions}

For each dimension, there is a pairwise comparison matrix that related e-vectors could be derived. The e-vectors from different matrixes are integrated into a new matrix as different columns, where the name of the column is the selected dimension. The new matrix, known as super-matrix, reflects the interdependencies of dimensions, which is revealed in Table 3 . For the matrix entry $a_{i, j}$, if $a_{i, j}=0$, then dimension $i$ has no influence on dimension $j$, if $a_{i, j}>0$, then $a_{i, j}$ is the relative importance of dimensions $i$ in influencing dimension $j$.

From Table 3, it is observed that the normalized weight of invoicing performance with respect to one-off cost is 0.1549 , which has the same value of the e-vectors in Table 2.

Table 3. Super-Matrix of Dimensions before Convergence

\begin{tabular}{llllllll}
\hline & OOC & MC & UC & CE & SP & EB & IP \\
\hline One-off cost (OOC) & 0.3999 & 0.0787 & 0.0616 & 0.0468 & 0.0802 & 0.0441 & 0.1014 \\
Monthly cost (MC) & 0.0454 & 0.3804 & 0.0616 & 0.0468 & 0.1580 & 0.0834 & 0.0497 \\
Unit cost (UC) & 0.0454 & 0.0444 & 0.4194 & 0.0885 & 0.1636 & 0.0429 & 0.0497 \\
Customer experience (CE) & 0.0933 & 0.1632 & 0.1490 & 0.4457 & 0.0428 & 0.1688 & 0.0497 \\
Supplier performance (SP) & 0.1772 & 0.2123 & 0.1068 & 0.1528 & 0.4699 & 0.1503 & 0.2378
\end{tabular}




\begin{tabular}{llllllll} 
Enterprise business (EB) & 0.0839 & 0.0398 & 0.0351 & 0.0468 & 0.0428 & 0.4271 & 0.0497 \\
Invoicing performance (IP) & 0.1549 & 0.0814 & 0.1664 & 0.1728 & 0.0428 & 0.0834 & 0.4617 \\
\hline
\end{tabular}

The next thing to do after the formation of the super-matrix is to find the stable solution for the weights of dimensions. Since the super-matrix is column stochastic, it could be converged through raising the super-matrix to the power $2^{k+1}$, where $k$ is a large enough number. The converged super-matrix of dimensions is shown in Table 4, after raising the super-matrix to the power 129.

From Table 4, it is observed that after the convergence, each column has a similar outcome. Supplier performance has the maximum stabilized weight $(0.2499)$ and customer experience has the minimum stabilized weight (0.0773). For clarity, the stabilized weight of dimensions $i$ in influencing the overall is defined as $I_{i}$.

Table 4. Super-Matrix of Dimensions after Convergence

\begin{tabular}{llllllll}
\hline & OOC & MC & UC & CE & SP & EB & IP \\
\hline One-off cost (OOC) & 0.1080 & 0.1080 & 0.1080 & 0.1080 & 0.1080 & 0.1080 & 0.1080 \\
Monthly cost (MC) & 0.1196 & 0.1196 & 0.1196 & 0.1196 & 0.1196 & 0.1196 & 0.1196 \\
Unit cost (UC) & 0.1304 & 0.1304 & 0.1304 & 0.1304 & 0.1304 & 0.1304 & 0.1304 \\
Customer experience (CE) & 0.1464 & 0.1464 & 0.1464 & 0.1464 & 0.1464 & 0.1464 & 0.1464 \\
Supplier performance (SP) & 0.2499 & 0.2499 & 0.2499 & 0.2499 & 0.2499 & 0.2499 & 0.2499 \\
Enterprise business (EB) & 0.0773 & 0.0773 & 0.0773 & 0.0773 & 0.0773 & 0.0773 & 0.0773 \\
Invoicing performance (IP) & 0.1683 & 0.1683 & 0.1683 & 0.1683 & 0.1683 & 0.1683 & 0.1683 \\
\hline
\end{tabular}

\subsection{Pairwise Comparison of Elements}

In this step, a series of pairwise comparisons are proposed to establish the relative importance of elements with respect to the dimension that the elements belong to. Table 5 illustrates the pairwise comparison matrix that the selected dimension is one-off cost. When the selected dimension is $k$, for the matrix entry $a_{i, j}$, the question asked to the experts is "considering the influence on dimension $k$, what is the relative importance of element $i$ when compared to element $j$." Altogether there are seven such pairwise comparison matrixes, one for each of the seven dimensions.

Table 5. Pairwise Comparisons of Elements under One-Off Cost

\begin{tabular}{llllll}
\hline & RBC & IC & ETC & AC & e-vectors \\
\hline Relationship Building Cost (RBC) & 1 & $1 / 7$ & $1 / 3$ & $1 / 2$ & $\mathbf{0 . 0 7 6 3 8}$ \\
Installation Cost (IC) & 7 & 1 & 2 & 4 & $\mathbf{0 . 5 3 0 5 1}$ \\
Employee Training Cost (ETC) & 3 & $1 / 2$ & 1 & 2 & $\mathbf{0 . 2 5 5 7 3}$ \\
Advertising Cost (AC) & 2 & $1 / 4$ & $1 / 2$ & 1 & $\mathbf{0 . 1 3 7 3 9}$ \\
\hline
\end{tabular}

Inconsistency 0.00288

From Table 5, it is observed that the relative importance of installation cost when compared to relationship building cost with respect to one-off cost is seven. From the derived e-vectors, it is observed that installation cost has the maximum influence (0.53051) and relationship building cost has the minimum influence (0.07638). For clarity, the relative importance of element $j$ in influencing dimensions $i$ is defined as $E_{i j}$.

\subsection{Pairwise Comparison of Alternatives}

In this step, a series of pairwise comparisons are proposed to establish the evaluation of different alternatives with respect to a selected element. Table 6 illustrates the pairwise comparison matrix that the selected element is invoice 
transportation cost. When the selected element is $k$ for the matrix entry $a_{i, j}$, the question asked to the experts is "considering the influence on element $k$, what is the relative effect brought by alternative $i$ when compared to alternative $j$." Altogether there are twenty seven such pairwise comparison matrixes, one for each of the twenty seven elements.

From Table 6, it is observed that the relative effect brought by alternative A when compared to alternative $\mathrm{B}$ with respect to invoice transportation cost is nine. From the derived e-vectors, it is observed that alternative $\mathrm{A}$ has the maximum evaluation (0.81818) on invoice transportation cost and both alternative $\mathrm{B}$ and alternative $\mathrm{C}$ have the minimum evaluation (0.09091). For clarity, the relative effect brought by alternative $k$ under element $j$ of dimension $i$ is defined as $A_{i j k}$.

Table 6. Pairwise Comparisons of Alternatives under Invoice Transportation Cost

\begin{tabular}{lllll}
\hline & A & B & C & e-vectors \\
\hline Invoicing Solution A (A) & 1 & 9 & 9 & $\mathbf{0 . 8 1 8 1 8}$ \\
Invoicing Solution B (C) & $1 / 9$ & 1 & 1 & $\mathbf{0 . 0 9 0 9 1}$ \\
Invoicing Solution C (C) & $1 / 9$ & 1 & 1 & $\mathbf{0 . 0 9 0 9 1}$ \\
\hline
\end{tabular}

\subsection{Calculation of the Overall}

After the pairwise comparison steps are completed, the overall is calculated from the desirability indices for each alternative invoicing solution. In general, the relative effect of an alternative with respect to different elements is summed up to evaluate its influence on related dimension, and this value is summed up to evaluate its influence on the overall. In this paper, the overall of alternative $k$ is mathematically represented as

$$
\text { overall }_{k}=\sum_{i \in e f f e c t i v e n e s s} \sum_{j \in i} D_{i} I_{i} E_{i j} A_{i j k}-\sum_{i \in \text { cossts }} \sum_{j \in i} D_{i} I_{i} E_{i j} A_{i j k}
$$

In the equation, $D_{i}$ is relative importance of dimensions $i$ with respect to the overall, $I_{i}$ is the stabilized importance weight of dimensions $i$ when considering the interdependencies of dimensions, $E_{i j}$ is the relative importance of element $j$ with respect to dimension $i$, and $A_{i j k}$ is the relative effect brought by alternative $k$ under element $j$ of dimension $i$.

The results are presented in Table 7. It is observed that alternative B is the mostsuited invoicing solution, since the overall of solution B (0.02286) is better than solution A (-0.001933) and solution C (0.020286). In a further consideration, solution B (0.009267) takes advantages in cost, when compared with solution A (0.030342) and solution $\mathrm{C}(0.012520)$, and solution $\mathrm{C}(0.032805)$ takes advantages in effectiveness when compared with solution A (0.028409) and solution B (0.032127). However, the advantages of solution $\mathrm{C}$ in evaluation could not make up its shortage in cost.

It is further observed that, invoice transportation cost, invoice transportation time and solution compatibility are the most weighted criteria, followed by previous experience, personnel cost, after-sale service quality, maximum flow, invoice document cost and reimbursement service quality. The main reasons that solution B has the highest evaluation are solution compatibility, after-sale service quality, invoice cycle time, installation cost and upgrade cost. In Figure 5, the comparison of alternatives is illustrated. Solution B and solution C have very similar character, while the most significant distinction is in monthly cost. 

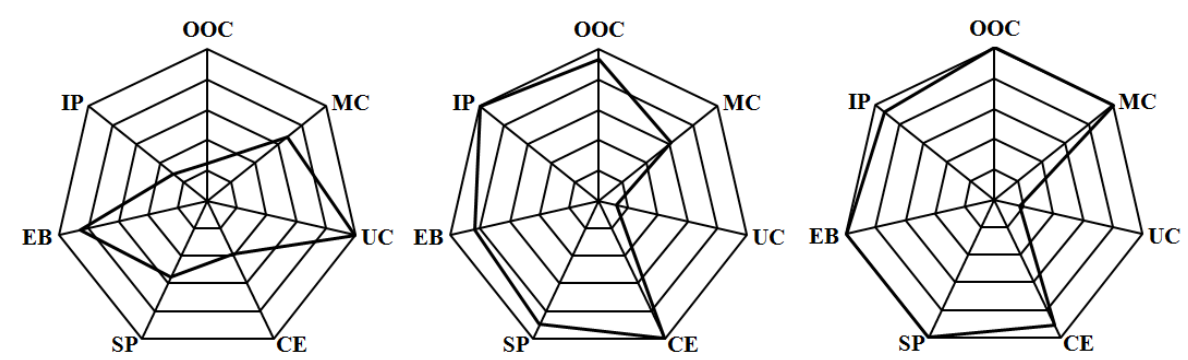

Figure 5. Comparison of Alternatives (Solution A, B and C)

As defined, solution B is to establish a self-built electronic invoicing solution, which has been calculated as the present best solution. The cost control, enterprise strategy and facilities of given enterprise contribute to this decision.

\section{Conclusions}

The evaluation of invoicing solutions is a multi-criteria problem for enterprise managers. They not only have to determine whether to reserve the paper-based invoicing process such as using tax control machine as in Golden Tax Project, or to adopt electronic invoicing process, but also have to select from several electronic invoicing providers or make the decision to establish a self-built electronic invoicing system. This evaluation model proposed in this paper involves criteria of Cost and Effectiveness, while Cost is consist of one-off cost, monthly cost and unit cost, and Effectiveness is consist of customer experience, supplier performance, enterprise business and invoicing performance. These criteria give a comprehensive analysis of the invoicing solution, and in the structure of this model, the weights of the seven dimensions could well reflect the characteristics of an enterprise, such as enterprise scale, trading volume, IT facilities and enterprise strategy. Then the differences in weights result in that a same invoicing solution has different evaluations toward different enterprises. In this way, enterprises could evaluate invoicing solutions according to their own situations.

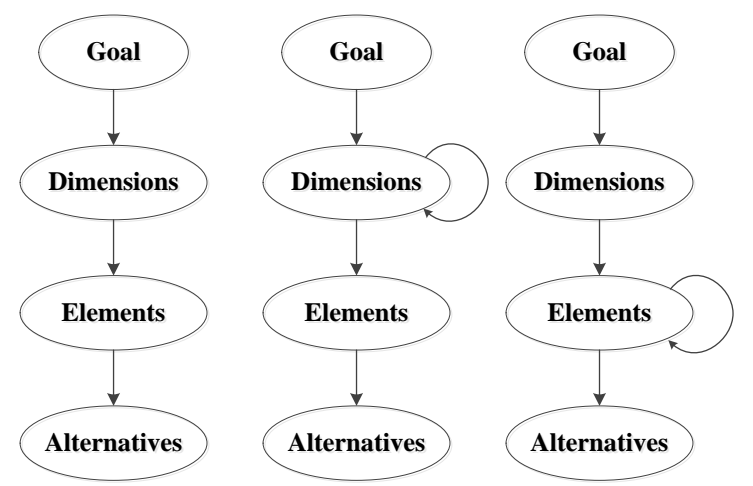

Figure 6. Model Structure

It is worth mentioning that, the three layer structure used in this model considers the interdependencies of dimensions (middle part of Figure 6), instead of those of elements (right part of Figure 6). Thus, a feedback system is constructed at the dimensions layer. Comparatively, the models that consider interdependencies at element layer will have higher accuracy, but more mathematical computations. For example, a model with $m$ dimensions and average $n$ elements for each dimension totally has $m n+2 m+1$ pairwise comparison matrixes in our model. But when considering the interdependencies of elements, the model will have $2 m n+m+1$ 
matrixes. In the evaluation of electronic invoicing solutions, it is enough to distinguish the effect brought by different solutions when the model only considers the interdependencies of dimensions. Therefore, in order to reduce the computational work, the interdependencies of elements are ignored.

This paper proposes an evaluation model for the selection of invoicing solutions. Compared with current models considering electronic invoicing or other similar cases, the proposed model enjoys the following advantages:

- This model is a specific evaluation model towards invoicing solutions. The criteria selected to structure this model can well describe the influences brought by a new invoicing process to an enterprise. Some special characteristics of invoicing process are introduced, such as invoice transportation costs, issuing reminder costs and reimbursement service quality. In this way, this model could be more suitable for invoicing solution evaluations.

- The alteration of criteria is resolved in this model. When the criteria of this model change according to the region and business scope of given enterprise, and even time. This ANP based model works well due to pairwise comparison adopted.

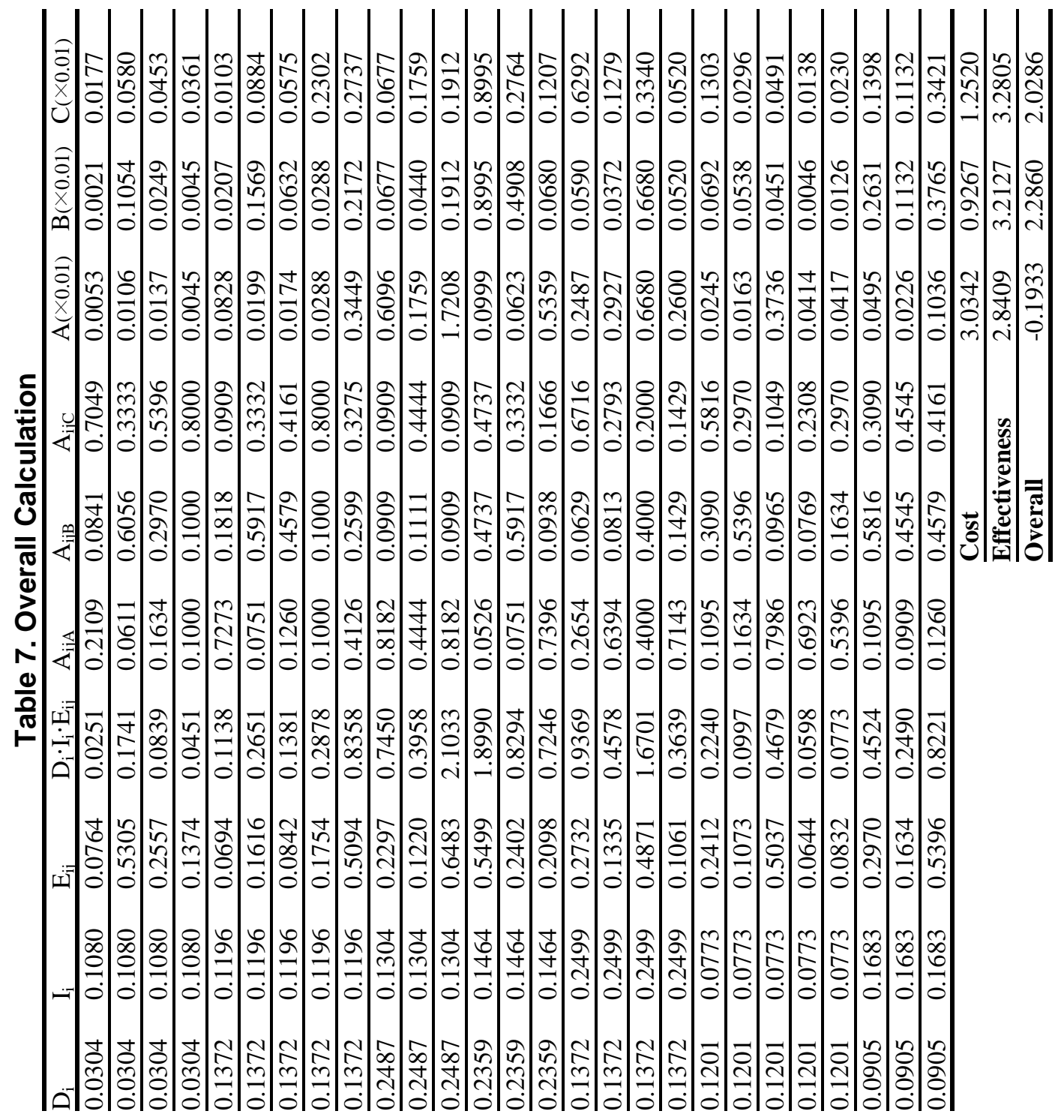




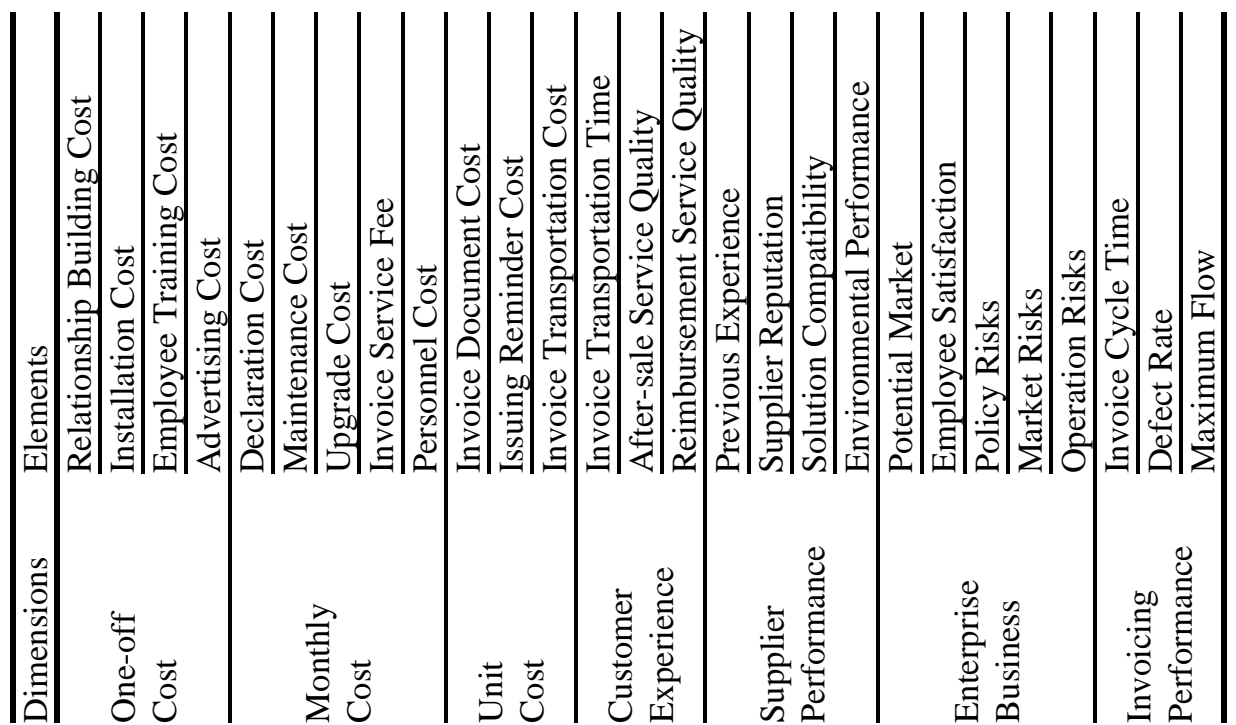

- The interdependencies of criteria in invoicing process are also considered. This ANP model lays out a structure of all the essential criteria that influence the result of an evaluation, and employs super-matrix to conduct the stabilized effect of the influence of different criteria.

- This model reduces the computation load compared with similar ANP models. This model is based on a three layer structure, and the interdependencies of dimensions are considered instead of elements, which results in a relatively small amount of pairwise comparison matrixes.

\section{Acknowledgements}

This work is supported by NELECT (National Engineering Laboratory for Ecommerce Technologies, Tsinghua Univ.) and DNSLAB of China Internet Network Information Center.

\section{References}

[1] R. Hill and I. Walden, "The draft UNCITRAL model law for electronic commerce: issues and solutions", Computer Lawyer, vol. 13, (2003), pp. 11-22.

[2] Y. Zeng, X. Guo, Y. Yang and H. Huang, "E-commerce tax collection and administration in China", 2012 International Conference on Information Management, Innovation Management and Industrial Engineering (ICIII) (2012), October 20-21; Sanya, China.

[3] D. Spanic, D. Ristic and B. Vrdoljak, "J. An electronic invoicing system", Proceedings of the 2011 11th International Conference on Telecommunications (ConTEL) (2011), June 15-17; Graz, Germany.

[4] C. Tanner, R. Wölfle, P. Schubert and M. Quade, "Current trends and challenges in electronic procurement: an empirical study", Electronic Markets (2008), vol. 18, pp. 6-18.

[5] European Commission, "European Electronic Invoicing (EEI) Final Report", European Commission Informal Task Force on e-Invoicing (2007).

[6] B. Koch, "E-Invoicing/E-Billing in Europe", Taking the next step towards automated and optimized processes. Billentis, Wil (2009).

[7] TrustWeaver AB. Tax-complaint global electronic invoice lifecycle management, (2010) October.

[8] M. Salmony and B. Harald, "E-invoicing in Europe: Now and the future" < Journal of Payments Strategy \& Systems (2010), vol. 4, pp. 371-380.

[9] K. W. Sandberg, O. Wahlberg and Y. Pan, "Acceptance of e-invoicing in SMEs", Engineering Psychology and Cognitive Ergonomics, (2009), pp. 289-896.

[10] U. Bertelè, A. Perego, U. Zanini, G. Tedesco, A. Salgaro, G. Calabria, D. Marazzi, E. Galati, E. Galbiati, G. Ferrari, S. Incantalupo and M. Tramelli, "Electronic invoicing as a keystone in the collaboration between companies", banks and PA", Observatory on Electronic Invoicing and Dematerialization Research Report 2008 (2008), School of Management Politecnico di Milano, Milano.

[11] A. Amid, S. H. Ghodsypour and C. O'brien, "Fuzzy multiobjective linear model for supplier selection in a supply chain", International Journal of Production Economics, vol. 104, (2006), pp. 394-407. 
[12] C. A. Weber, J. R. Current and W. C. Benton, "Vendor selection criteria and methods", European journal of operational research, vol. 50, (1991), pp. 2-18.

[13] T. L. Saaty, "Decision making - the analytic hierarchy and network processes (AHP/ANP)", Journal of systems science and systems engineering, vol. 13, (2004), pp. 1-35.

[14] T. L. Saaty, "Making and validating complex decisions with the AHP/ANP", Journal of systems science and systems engineering, vol. 14, (2005), pp. 1-36.

[15] T. L. Saaty, "Decision making with dependence and feedback: The analytic network process", Pittsburgh, PA: RWS Publications (1996).

[16] T. L. Saaty, "The Analytic Hierarchy Process", New York: McGraw-Hill (1980).

[17] S. Berutti, "Electronic invoicing and digital archiving services: a provider selection model", Master Thesis, Polo territoriale di como, Italy (2012).

[18] T. L. Saaty, "Fundamentals of the analytic network process - multiple networks with benefits, costs, opportunities and risks", Journal of systems science and systems engineering, vol. 13, (2004), pp. 348379.

[19] R. Ramanathan, "A note on the use of the analytic hierarchy process for environmental impact assessment”, Journal of Environmental Management, vol. 63, (2001), pp. 27-35.

[20] H. Kinijarvi, P. Hallikainen and E. Penttinen, "Supporting the Supplier Scheduling Decisions in the EInvoicing Implementation Projects-an Application of the ANP Method. 2011 44th Hawaii International Conference on System Sciences (HICSS) (2011), Jan 4-7, Kauai, HI, Hawaii, USA.

[21] Ş. Erdoğmuş, M. Kapanoglu and E. Koc, "Evaluating high-tech alternatives by using analytic network process with BOCR and multiactors. Evaluation and Program Planning, vol. 28, (2005), pp. 391-399.

[22] I. Dikmen, M. T. Birgonul and B. Ozorhon, "Project appraisal and selection using the analytic network process", Canadian Journal of Civil Engineering, vol. 34, (2007), pp. 786-792.

[23] C. Liang and Q. Li, "Enterprise information system project selection with regard to BOCR", International Journal of Project Management, vol. 26, (2008), pp. 810-820.

[24] C. Sun, Y. Pan and R. Bi, "Study on third-party logistics service provider selection evaluation indices system based on analytic network process with BOCR", 2010 International Conference on Logistics Systems and Intelligent Management (2010), January 9-10, Harbin, China.

[25] O. Ustun and E. A. Demirtas, "Multi-period lot-sizing with supplier selection using achievement scalarizing functions", Computers \& Industrial Engineering, vol. 54, (2008), pp. 918-931.

[26] L. M. Meade and J. Sarkis, "Analyzing organizational project alternatives for agile manufacturing processes: an analytical network approach", International Journal of Production Research, vol. 37, (2008), pp. 241-261.

[27] L. M. Meade and A. Presley, "R\&D project selection using the analytic network process", IEEE Transactions on Engineering Management, vol. 49, (2008), pp. 59-66.

[28] S. Jharkharia and R. Shankar, "Selection of logistics service provider: An analytic network process (ANP) approach", Omega, vol. 35, (2007), pp. 274-289.

[29] K. Y. Chen and W. T. Wu, "Applying analytic network process in logistics service providers selection-a case study of the industry investing in Southeast Asia", International Journal of Electronic Business Management, vol. 9, (2011), pp. 24-36.

[30] T. L. Saaty and L. G. Vargas, "Decision making with the analytic network process", Springer (2006).

[31] A. H. Lee, "A fuzzy supplier selection model with the consideration of benefits, opportunities, costs and risks", Expert systems with applications, vol. 36, (2009), pp. 2879-2893.

[32] A. Das and L. Buddress, "Evaluating Prospective e-Providers: An Empirical Study", Journal of Supply Chain Management, vol. 43, (2007), pp. 31-46.

[33] C. Bai and J. Sarkis, "Integrating sustainability into supplier selection with grey system and rough set methodologies", International Journal of Production Economics, vol. 124, (2010), pp. 252-264.

[34] J. J. Nienhuis and C. Bryan, "E-invoicing 2010: European Market Guide", Paris: Innopay and Euro Banking Association (2010).

[35] M. Sonmez, "Review and critique of supplier selection process and practices", Loughborough University (2006).

[36] P. K. Humphreys, Y. K. Wong and F. T. S. Chan, "Integrating environmental criteria into the supplier selection process", Journal of Materials Processing Technology, vol. 138, (2003), pp. 359-356.

[37] C. Lu and Z. Hou, "Research on Information Security System in the Third Phase of Golden Tax Project", Microcomputer Information, vol. 6, (2008), pp. 29.

[38] K. Cheng and J. Luo, "The Development and Improvement of China's Golden Taxation Project", Applied Mechanics and Materials, vol. 291, (2013), pp. 2932-2935.

[39] S. Schenkerman, "Avoiding rank reversal in AHP decision-support models", European Journal of Operational Research, vol. 74, (1994), pp. 407-419.

[40] R. F. Dyer and E. H. Forman, "Group decision support with the analytic hierarchy process", Decision support systems, vol. 8, (1992), pp. 99-124. 


\section{Authors}
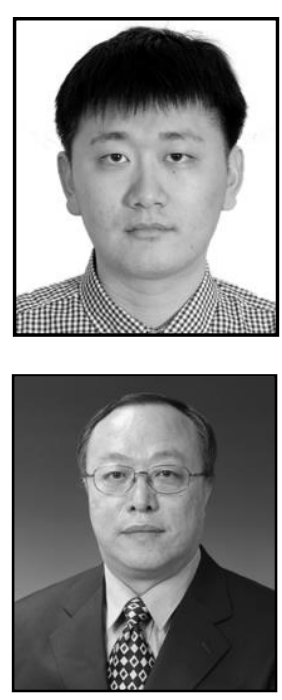

Yueting Chai, he was born in China, 1964. He earned his Doctor's degree in Automation at Tsinghua University in 2004 and served as deputy chief engineer of National CIMS Engineering Research Center since 1996. Professor Chai is now the director of National Engineering Laboratory for E-Commerce Technologies with a focus on electronic commerce and modern logistics.

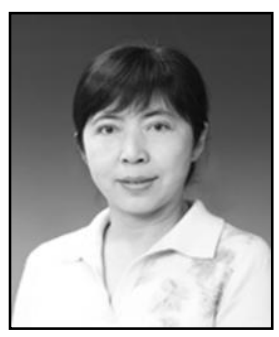

Yi Liu, he was born in China, 1966. She earned her Master's degree in Automation at Tsinghua University in 1991. Yi Liu becomes associate professor in Department of Automation at Tsinghua University from 1994. Associate Professor Liu is now focusing on electronic commerce and supply chain management.

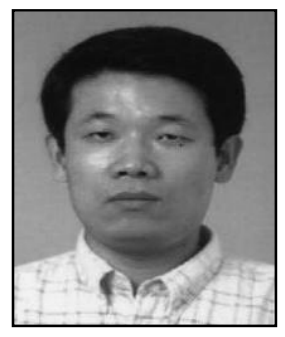

Hongbo Sun, was born in Fuping, China, on February 13, 1977. He received the B.S. degree in information science from Beijing Institute of Technology, Beijing, China, in 1998 and the M.S. degree in software engineering and the Ph.D. degree in control science from Tsinghua University, Beijing, in 2005 and 2011, respectively. He was a Postdoctoral Researcher with the National CIMS ERC, Tsinghua University during 2011 to 2014. He is currently an Associate Professor of College of Computer and Control Engineering, Yantai University, Yantai, Shandong, China. His research interests include system integration, artificial intelligence, algorithms, large-scale simulation, and e-commerce. 
International Journal of $u-$ and e- Service, Science and Technology Vol.8, No.4 (2015) 